2020-07-08

\title{
Rethinking legibility in the era of digital mobile maps: An empirical study
}

\author{
Ahmadpoor, $\mathrm{N}$
}

http://hdl.handle.net/10026.1/15758

10.1080/13574809.2020.1777847

Journal of Urban Design

Taylor \& Francis (Routledge)

All content in PEARL is protected by copyright law. Author manuscripts are made available in accordance with publisher policies. Please cite only the published version using the details provided on the item record or document. In the absence of an open licence (e.g. Creative Commons), permissions for further reuse of content should be sought from the publisher or author. 
Running head: Urban Form, Legibility, and Digital Maps

(In Press) Journal of Urban Design

Rethinking legibility in the era of digital mobile maps: An empirical study

\author{
Negar Ahmadpoor ${ }^{a, b}$ \\ Alastair D. Smith ${ }^{\mathrm{C}}$ \\ Tim Heath ${ }^{\mathrm{b}}$
}

${ }^{\mathrm{a}}$ School of Engineering and Built Environment, Anglia Ruskin University, UK

${ }^{\mathrm{b}}$ Department of Architecture and Built Environment, University of Nottingham

${ }^{\mathrm{c}}$ School of Psychology, University of Plymouth, UK

Corresponding Author: Email address: negar.ahmadpoor@anglia.ac.uk 


\begin{abstract}
This report examines the role of environmental legibility in an era where digital mobile maps guide many everyday journeys. We present data from a real-world navigational experiment, where participants followed urban routes either by using digital maps, or information in the world around them. They then completed an in-field task that probed recognition for environmental features along the routes. As predicted, participants in the digital map group demonstrated poorer memory for elements that underlie legibility, across landmarks, paths, and nodes. However, recognition in this group was moderated by individual characteristics of these elements, suggesting a role for legibility in memory. We discuss the implications of these results for the design of urban intersections that can militate against varied navigational experiences.
\end{abstract}




\section{Urban Legibility and GPS}

It was Kevin Lynch (1960), in his classic urban planning treatise 'The Image of the City', that proposed the concept of 'legibility' within the built environment. This describes a structural quality that helps people to better comprehend a particular physical space, and an environment with a high legibility factor enables people to form a more accurate representation of it in their minds and affords more efficient navigation. According to Lynch, the effects of legibility are dynamic, such that changes in the complexity of a built environment may cause fluctuating levels of difficulty for a navigator. This was supported in a study by Weisman (1981), who found that low legibility urban settings had less clear spatial organisation which resulted in the urban setting being less accurately comprehended by people navigating such environments. In the 60 years since its introduction, this concept has informed the design of built environments, providing a framework for planners and designers to create more legible places that people can comprehend and navigate easily.

In recent years, however, some aspects of urban navigation appear to be supported less by the legibility of the environment itself, and more by digital navigation systems. Indeed, navigational solutions that use the Global Positioning System (GPS) to help individuals traverse an environment have become omnipresent tools in modern society. This is unsurprising, since the process of forming a stable mental representation of navigational space has long been considered attentionally demanding (Downs and Stea 1973). Digital navigation systems offer a useful means to offload cognitive effort, whilst also providing a level of accuracy that can greatly improve navigational experiences in novel or complex environments (Allen, 1999; Speake, 2015). Such is the apparent power of these solutions that they seemingly bypass the very need for a space to be legible to the navigator, which raises a core question about the future of such a fundamental design principle. In the present research we, therefore, investigated how environmental legibility affects people's 
navigational experiences when they use digital mobile maps ${ }^{1}$. We also consider how legibility should be accounted for in designing (or redesigning) our current and future cities for a society that is more dependent upon more digital navigation.

Empirical assays of the effects of digital maps on urban navigation have mostly focused on the accuracy of spatial knowledge acquisition - that is, the quality of the mental representations formed by people when navigating with digital assistance. For example, a study by Brügger, Richter and Fabrikant (2019) revealed that although digital maps were of a clear benefit to navigational performance (e.g. increased success in finding destinations, saving time, decreasing stress level, etc.), they had a detrimental effect on the acquisition and retention of environmental knowledge, as well as people's ability to attend to their surroundings. Similar effects have been reported in a variety of other studies (Ahmadpoor and Smith, 2020; Ishikawa and Takahashi, 2013; Parush, Ahuvia and Erev, 2007b; Klippel, Hirtle and Davies, 2010; Ahmadpoor and Heath, 2018; Aslan et al. 2006; Ishikawa et al., 2008; Krüger et al., 2004; Münzer et al., 2006; Willis et al., 2009; Ruginski et al., 2019), and it is clear that they are not simply a product of using any form of external representational system. Münzer et al. (2006), for instance, found that individuals using physical maps exhibited superior spatial orientation and survey knowledge compared to those using digital navigation systems. This was supported by Ishikawa et al. (2008), who compared the spatial knowledge of navigators following a route from a navigational system, direct experience, or paper maps. Compared to participants using paper maps or direct experience, participants navigating using GPS systems recalled fewer features of their surroundings, and it was argued that this was a result of them not needing to attend to as much of their environment in order to successfully follow a route. In turn, it was suggested that the information that was encoded along the way was less likely to be consolidated into an enduring spatial representation (see also: Dickmann (2012)).

\footnotetext{
1 The information provided by mobile navigation systems can be in different formats such as texts, audio services, maps, pictures, etc. These formats affect differently the acquisition of spatial knowledge and success of way finding (Li, 2006). This research focuses on using the 'digital map formats' such as Google maps, as this widely used in pedestrian navigation (Kalin \& Frith, 2016).
} 
Accounting for the presence of detrimental effects of digital mapping upon spatial knowledge, some researchers have attempted to devise systems that are less likely to attenuate the formation of mental representations. For example, Löwen, Krukar and Schwering (2019) tested the use of digital maps that accentuated local (i.e. landmarks located along the route and at decision points such as an intersection) and global features (i.e. structural regions and global landmarks), and found them to support both visual and spatial knowledge acquisition, compared to standard solutions. An alternative to emphasising useful features is to provide more autonomy in navigational decisionmaking, as highlighted by Bakdash, Linkenauger and Proffitt (2008). They found that active decisionmaking, combined with an illustration of potential consequences of navigational decisions, also resulted in better spatial knowledge acquisition. Such differences in levels of automation and autonomy were specifically addressed by Brügger et al (2019), who classified 'higher-level' systems as those that provided more automatic guidance (i.e. in route planning), whilst 'lower-level' systems left more decisions to the navigator. Their comparison between systems revealed a similar picture that of Bakdash et al. (2008), with higher-level navigational systems appearing to impair the acquisition of sufficient spatial knowledge for pedestrian navigators to reverse their route without making navigational errors.

Interestingly, although this broad range of studies has revealed a general pattern of relatively impaired environmental knowledge in digital map users, there has been little focus on whether this effect is moderated by the nature of the environment itself. For example, one might expect to observe little contrast between digital map users and other navigators in a setting with high environmental legibility, but a greater difference when legibility is lower and, therefore, requires more cognitive effort to accurately encode. We recently examined this very issue, using a sketch map method to interrogate the accuracy of participants' mental representations of a novel urban route (Ahmadpoor and Smith, 2020). Participants followed a route between key urban landmarks that was either specified by a mobile map solution or through direct experience of the environment 
(e.g. using street signs). In line with previous research, we found the participants following a route specified by a mobile map produced less accurate sketches of the environment they had traversed, with poorer representation of landmarks, paths, and intersections. However, our findings also revealed that this relationship was indeed moderated by the legibility of the environment, with a greater difference between groups at points of lower legibility, such as intersections without salient landmarks, or with a greater number of branching streets. As a result of this, we proposed some suggestions for urban design guidelines as how they could enhance legibility for different types of users.

In the present report, we present alternative data from the same experimental procedure, in order to refine our understanding of the behaviours observed and produce a more comprehensive characterisation of the interaction between legibility and digital map use. The potential need for this refinement lies in the method that we chose to focus on in our previous report (Ahmadpoor and Smith, 2020); namely, the use of sketch maps to examining mental representation of space. Whilst this form of data provides a very rich assay of an individual's configural understanding of an environment and its contents, the veracity of the data arguably depends upon a number of factors that may be subject to some inter-individual differences, such as the vividness of visual imagery (Cui et al., 2007) and drawing ability (van Sommers, 1984). A more sensitive measure might, therefore, be to test recognition memory for environmental features, as used by Cohen and Schuepfer (1980) and Evans et al. (1984) as an assay of memory for urban landmarks. This allows for tighter control over the means by which spatial knowledge is probed, and also provides multiple trials over which a measure of central tendency can be derived. Here, we present recognition data, for participants navigating with digital assistance or by direct experience, and compare it to the sketch maps produced.

In order to relate recognition performance to the legibility of the environment, we employed a classificatory system, detailed in our previous report (Ahmadpoor \& Smith, 2020), which devolves legibility into three core elements: landmarks, paths, and nodes (Lynch, 1960; Gärling, Lindberg and 
Mäntylä, 1983; Passini, 1984; Appleyard, 1970; Golledge, 1978; Golledge et al., 2000; Haque, 2003). The concept of landmarks (one of the elements in Lynch's theory) has seen a vast amount of research (Lynch, 1960; Nothegger, Winter and Raubal, 2004; Presson and Montello, 1988; Raubal and Winter, 2002; Siegel and White, 1975) that has formalized it from both a perceptual and architectural perspective, confirming the importance of landmarks as an important reference point. Nodes which are the key directional decision-making points that are situated within an environment. Nodes tend to be a convergence point for a number of paths and examples include cross-roads, crossings, and junctions. Finally, paths are the channels that provide the ability (or potential) to traverse, such as walkways, streets, canals, or railroads. These three factors can themselves be subdivided into different types (see Table 1), and one can see that some of these have received more theoretical discussion than others. Landmarks have mostly been examined with regards to the role of visibility, and paths have been explored in terms of their length, the number of directional changes, and the presence of external/internal landmarks along them. Relatedly, nodes have been most scrutinized for the placement of landmarks at the node itself, as well as the number of paths entering the node.

By presenting a different type of data in the present report, and taking advantage of the methods used by experimental psychologists, this study attempts to achieve four core aims. The first is to examine whether there is a difference in recognition memory for different elements (i.e. landmarks, nodes, and paths) of an unfamiliar urban setting, depending on whether individuals navigated using digital maps on mobile devices (known as the Digital Map group: DM), or without GPS assistance (known as Direct Experience group: DE). The second aim was to distinguish whether there is a general relationship between attributes of environmental legibility and visual recognition ability in digital map users. Despite predicting that the DE group would have a higher level of visual recognition ability, it was expected that any contrast would be mediated by environmental legibility, resulting in less difference between groups when participants were in more legible areas. The third aim was to compare the recognition test data to the sketch map results of our previous study, in 
order to ascertain whether they provide a similar characterisation of participant performance. The

fourth, and final, aim was to consider the results of this study in relation to urban design guidelines.

Table 1. A taxonomy of the underlying attributes of paths, nodes, and landmarks that were focused upon in the research (adapted from Ahmadpoor and Smith, 2020).

\begin{tabular}{|c|c|c|c|}
\hline \multicolumn{4}{|c|}{ Path } \\
\hline Attributes & Explaination & Diagram & Examples from the site \\
\hline Length & $\begin{array}{l}\text { Length of the path is a factor } \\
\text { that can influence people's } \\
\text { spatial knowledege } \\
\text { acquisition (Evans et al. } \\
\text { 1984b; Haque et al. } \\
\text { 2006,Guérard and } \\
\text { Tremblay, 2012). }\end{array}$ & & \\
\hline $\begin{array}{c}\text { Number of } \\
\text { turns }\end{array}$ & $\begin{array}{l}\text { Number of turns along a } \\
\text { path (can also occur at an } \\
\text { intersection) (Evans et al. } \\
\text { 1984b; Haque et al. 2006, } \\
\text { Jansen-Osmann and } \\
\text { Wiedenbauer, 2004) } \\
\text { (Jansen-Osmann and } \\
\text { Wiedenbauer, 2004). }\end{array}$ & & \\
\hline $\begin{array}{c}\text { Route with } \\
\text { internal } \\
\text { landmark }\end{array}$ & $\begin{array}{l}\text { Paths containing inernal } \\
\text { landmarks (i.e. landmarks in } \\
\text { the immediate context of the } \\
\text { path) (Westerbeek and Maes } \\
\text { 2013; Klippel and Winter } \\
\text { 2005). }\end{array}$ & & \\
\hline $\begin{array}{c}\text { Route with } \\
\text { external } \\
\text { landmark }\end{array}$ & $\begin{array}{l}\text { Paths with visual access to } \\
\text { extenal landmarks (i.e. } \\
\text { landmarks which are not } \\
\text { located in the immediate } \\
\text { context of the path, but } \\
\text { visible to people as they } \\
\text { walk along the path) } \\
\text { (Westerbeek and Maes } \\
\text { 2013; Klippel and Winter } \\
\text { 2005). }\end{array}$ & & \\
\hline
\end{tabular}




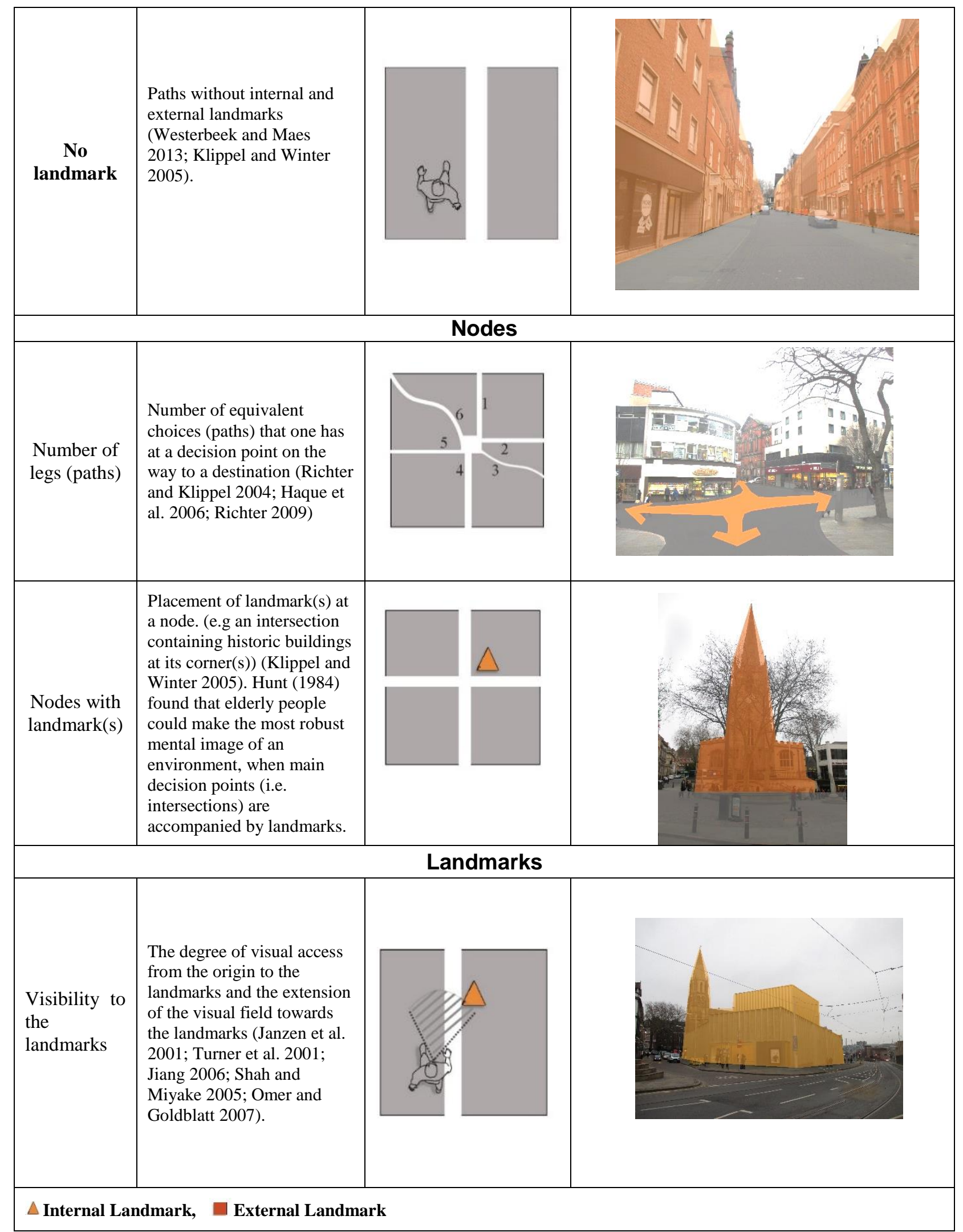




\section{Urban Design and Legibility}

Legibility has been considered as one of the main urban design objectives in developing both new urban projects and regeneration projects (e.g. Responsive Environments: A Manual for Designers (Bentley, 1985); Urban Design Compendium (Davies, 2000); Department of the Environment and Transport and the Regions (2000)). Indeed, the DETR state that an urban design objectives is "to promote legibility through development that provides recognisable routes, intersections and landmarks to help people find their way around" (Department of the Environment and Transport and the Regions, 2000: 15). This section will explore how landmarks, nodes, and paths are considered in urban design practice in order to inform how our research can contribute to urban design guidelines regarding legibility in the environments where users are increasingly using digital navigation systems.

Landmarks are discussed in many urban design documents (Department of the Environment andTransport and the Regions, 2000; Llewelyn Davies, 2000; CABE, 2003; Bristol City Council, 2003; Sheffield City Council, 2004; The Essex Design Guide, 2018) and these include a number of common guidelines and advice regarding the design of landmarks in different urban environments. These include the importance of placing landmarks in places that are visually accessible (Department of the Environment and Transport and the Regions, 2000) to increase the legibility of an area as well as enriching sense of place. The removal of all the barriers that block visual links between places is also encouraged as visual connections make it easier for people to find their way around. Views should, where possible, focus on memorable buildings and landscape features as this can be integral to wayfinding and also reinforce the sense of place (Department of the Environment andTransport and the Regions, 2000; CABE and DETR, 2001; Nottingham City Council, 2009). Another factor related to landmarks is the enhancement of the landmarks and memorable buildings along main streets. This helps to increase not only the readability of those landmarks but also the quality, experience and legibility of the streets themselves (Haque, Kulik and Klippel, 2006; Guérard et al., 2012). The 
enhancement of landmarks can include the use of different building materials or colours in comparison to their surrounding context to increase the visibility of the landmark ( Bristol City Council, 2018; Nottingham City Council, 2019).

The clarity of paths is also seen as an important factor. Indeed, it is commonly pointed out that paths with a clear 'start' and 'end' tend to be comprehended better by navigators (Haq and Zimring, 2003; Richter and Klippel, 2004; Richter, 2009; Gao et al., 2020; Ralphs et al., 2020). It is therefore recommended, where possible, to have short streets so that the end of the street is visible to the navigator thereby increasing the legibility of the area. Nodes (e.g. junctions) as decision-making points where people need to make spatial decisions are also key urban design elements. As such, the clarity of the main junctions in an environment is essential to ease people's navigation and decrease people's confusion regarding wayfinding. The clarity of a junction can be increased by designing clear streets that enter the junction and also by enhancing the visual quality of buildings that form the junction (Haque and Zimring, 2003; Richter and Klippel, 2004; Richter, 2009; Ahmadpoor and Shahab, 2019). The design of the corners to junctions is considered to improve the legibility of the junction and the wider context. Well-designed corners can augment legibility by creating visual interest and contributing to a distinctive identity by providing identity and points of orientation for people. Making these buildings higher than the surrounding buildings can emphasise their importance and increase legibility together with the location of public uses such as shops, governmental buildings, etc. on the corners of busy streets to increase activity and improve local identity (Department of the Environment andTransport and the Regions, 2000; CABE, 2003).

Although in most urban design documents, it is recommended to have clear paths and junctions to increase legibility of the environment, some places earn their charm from their lack of clarity in routes and junctions. These are the places where people can experience some specific spatial qualities such as serendipity, surprise, and discovery. It is important therefore, to understand that 
the design process needs to consider the fact that people comprehend, interpret and enjoy an environment in different ways (Shahab et al., 2019a; Shahab et al., 2019b). For example, different genders, different age groups, residents or visitors, and people from different cultural backgrounds can experience the same environment differently with varying levels of comfort. This research examines how people using digital map systems understand the built environment differently to those without the aid of such devices and the extent to which the environmental legibility of paths, nodes, and landmarks affect their knowledge of the built environment. The next section discusses the methods utilised for data collection, followed by the results which present the analyses and findings of the study. The discussion section will then identify how the research findings can contribute to urban design practice.

\section{Research Method}

\section{Participants}

There were a total of 76 participants ( 38 males and 38 females), comprised of first year undergraduate and postgraduate students attending the University of Nottingham. The participants were aged between 18 to 28 years, with a mean age of 23 years $(M=22.86, S D=3.36)$. The participants had been opportunistically sampled according to the following criteria: (a) they were born and raised in the UK, thus increasing the likelihood that they were used to the culture of the neighbourhood; (b) they had not previously entered the study area; (c) they were familiar using digital maps in an urban setting; and, (d) they were right handed. Upon meeting these criteria, participants were evenly (males and females) and quasi-randomly distributed between the Digital Map (DM) and the Direct Experience (DE) experimental groups.

To provide a measure of individual differences in self-reported navigational ability (Hegarty et al., 2002; Wen, Ishikawa and Sato, 2011), the Santa Barbara Sense-of-Direction Scale (SBSOD: Hegarty et 
al., 2002) was administered to participants. The SBSOD comprises fifteen statements, seven of which are positive (i.e. "I am very good at giving directions") and the remaining eight are negative (i.e. "I very easily get lost in a new city"). Responses are provided along a 7-point Likert scale, which allows participants to convey their level of agreement with each statement (ranging from 1 'strongly agree' to 7 'strongly disagree'). Each participant received an email containing the SBSOD and completed it (upon which the individual participants mean answer for the fifteen SBSOD statements was calculated) before partaking in the study. The scores for the negative SBSOD statements were reverse-coded so that a higher score (ranging from 1-7) conveyed a better self-reported sense of direction. In order to equate general spatial abilities across both samples, it was ensured that the SBSOD scores were not significantly different between groups (see Table 2).

Table 2. Results of $t$-test for comparing the mean of SOD between the two groups

\begin{tabular}{cccccccc}
\hline DM M (SD) & DE M(SD) & $\Delta M$ & $\mathrm{t}$ & $\mathrm{df}$ & $p$-value & Cohen's d \\
\hline $4.710(0.465)$ & $4.632(0.492)$ & 0.08 & 0.725 & 74 & 0.156 n.s. & 0.17 small \\
& & & & & & & \\
effect
\end{tabular}

n.s.=not significant $(p>.05)$.

Each participant provided written informed consent before beginning the study, and full ethical approval for the research was provided by the University of Nottingham Ethics Committee for human-based research. Upon completion of the study, participants received a gift voucher as remuneration for their involvement.

\section{Environmental Setting}

The study was conducted in a 14-hectare area in Nottingham city centre, which was previously unknown to the participants. The locality has a medieval historic morphological pattern and comprises both modern and historic architecture. There were twenty streets, eighteen key street junctions, and over 350 buildings in the testing area. The selected route consisted of 8 target 
locations, as shown in Figure 1 (the order in which participants were asked to visit them is also highlighted in Figure 1). Figure 2 presents the integrated sequences (i.e. various sequences linked together) that participants went through.

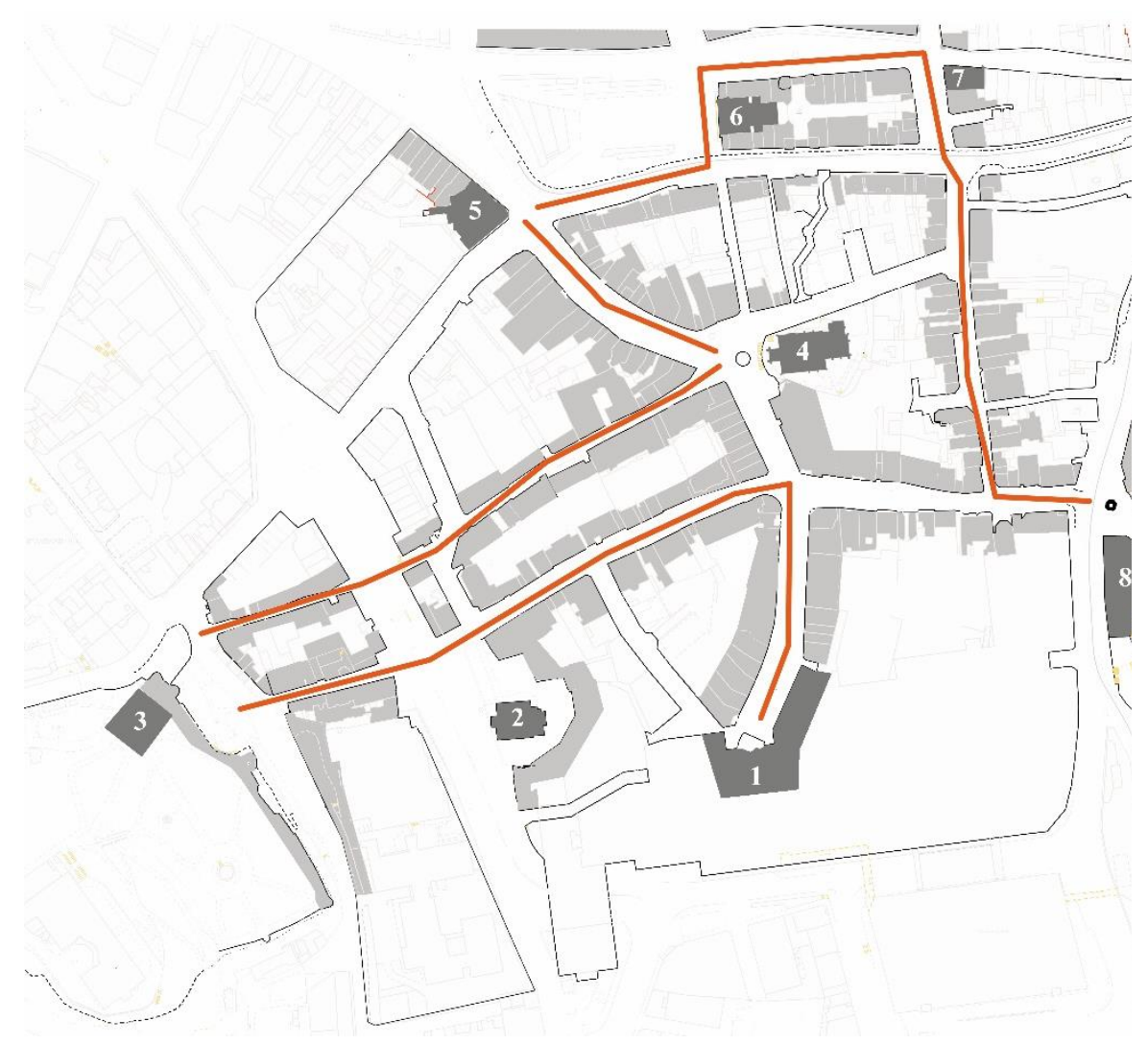

Experimental paths
Buildings passed by
The experimental destinations

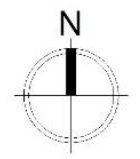

Figure 1: Map illustrating the eight locations and the order in which they were to be visited: 1) Broadmarsh Shopping Centre; 2) St Nicholas' Church; 3) Nottingham Castle; 4) St Peter's Church; 5) Nottingham Central Library; 6) Nottingham Council House; 7) Pelham Street House; 8) Nottingham Contemporary art gallery. 


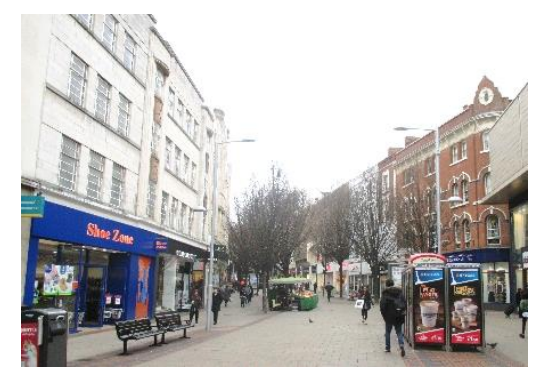

a

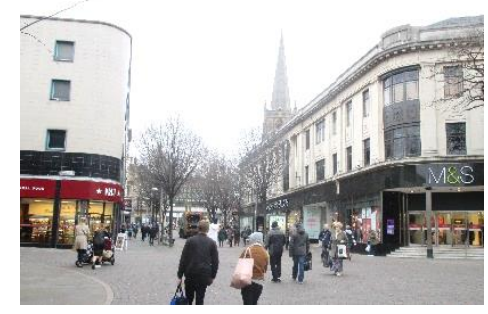

C

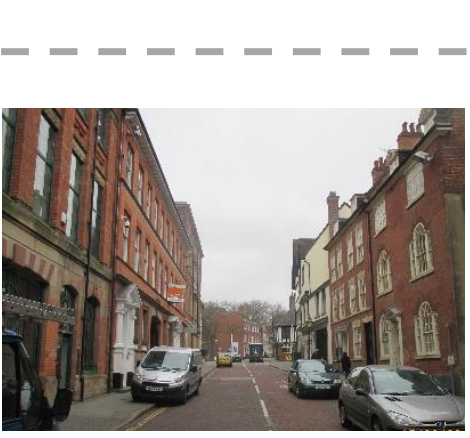

a
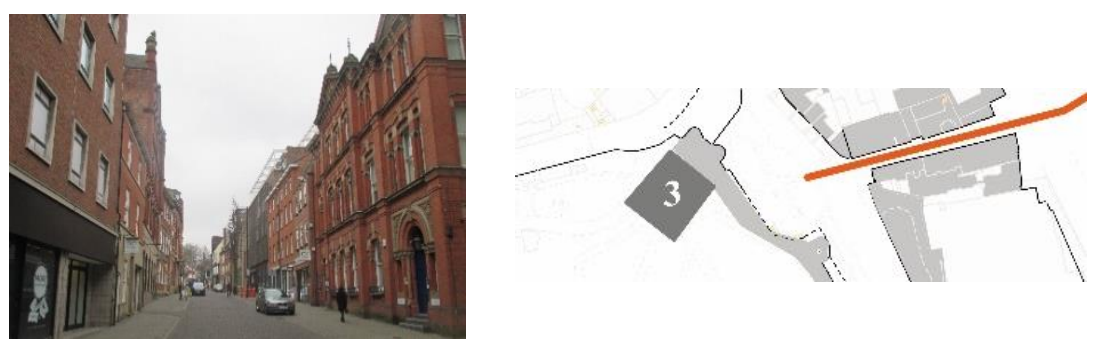

b
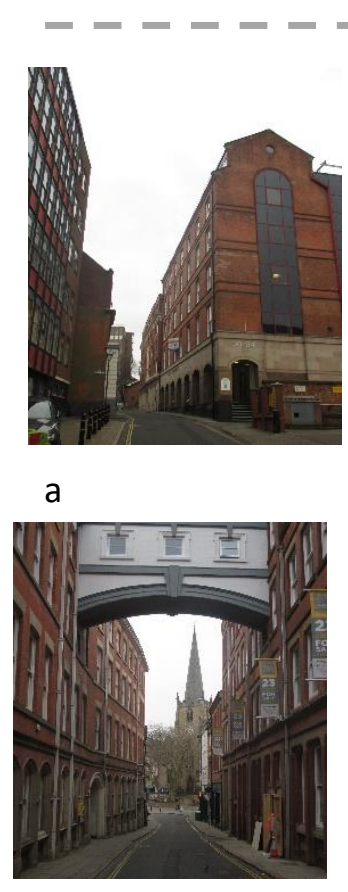

b
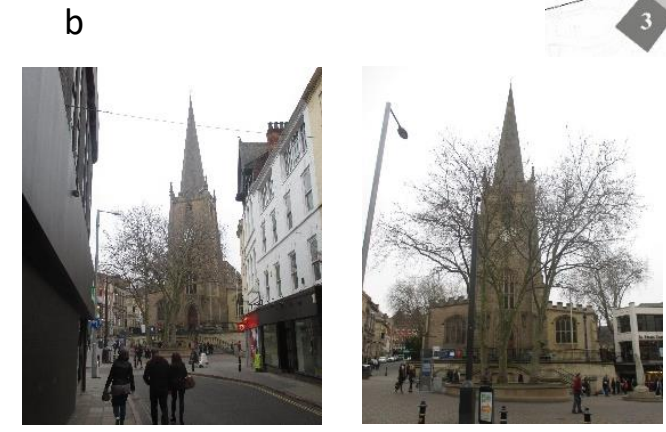

C

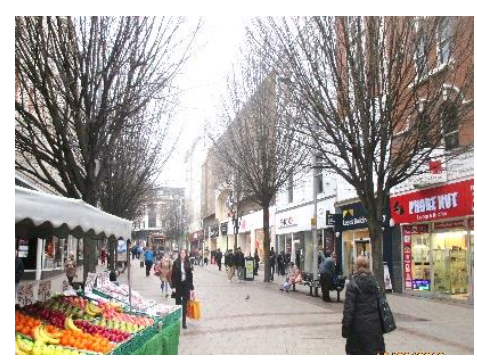

b

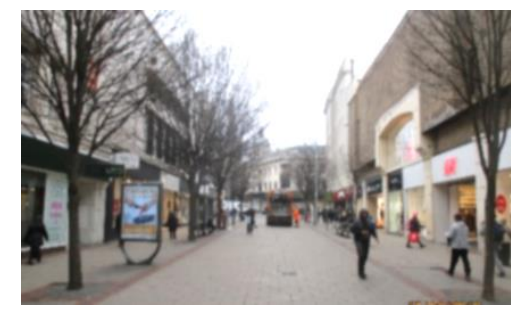

d
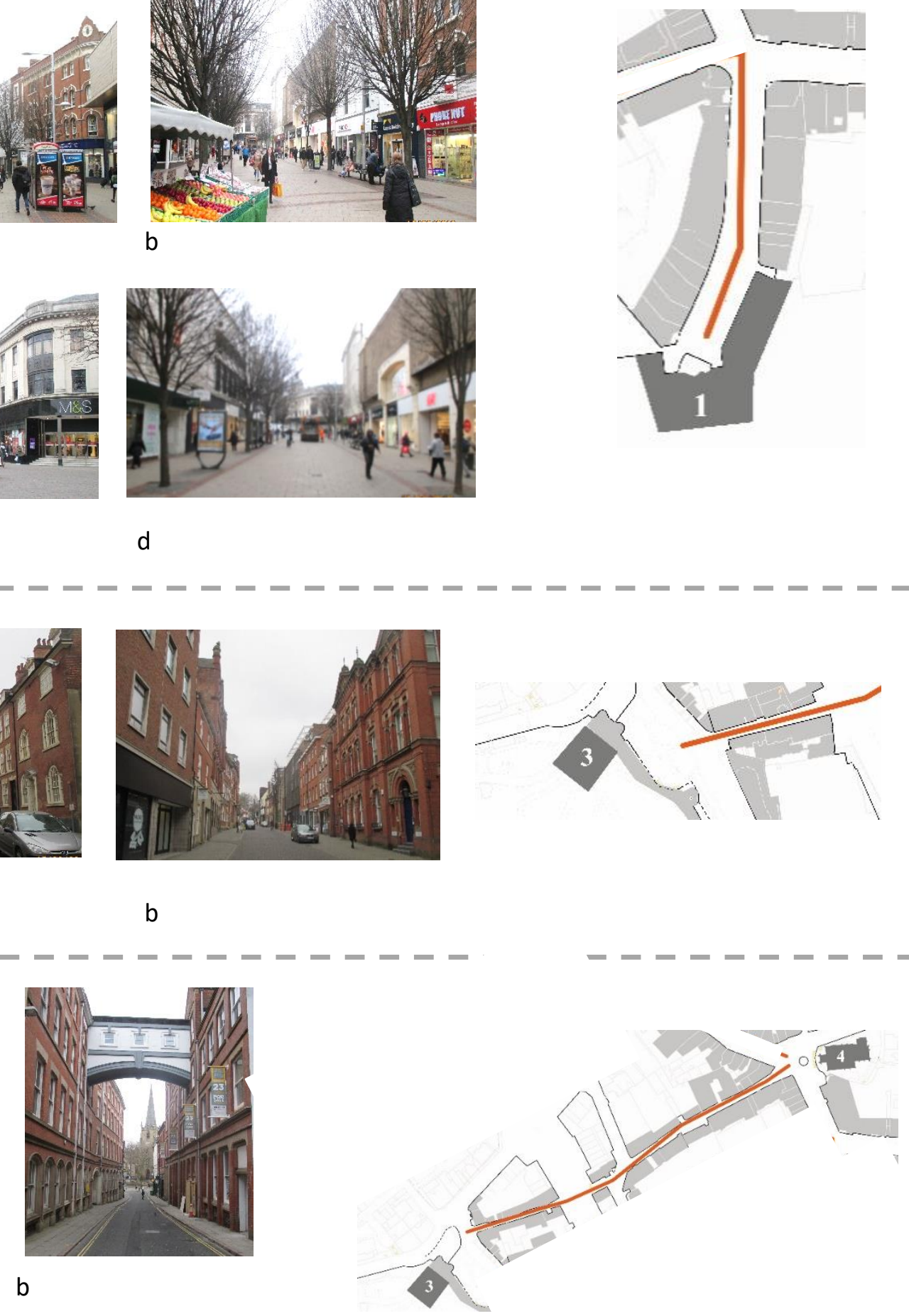

d

e 


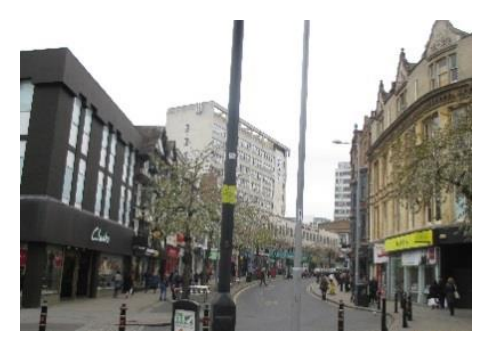

a

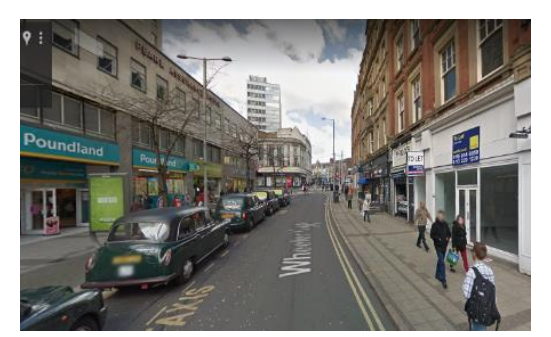

b
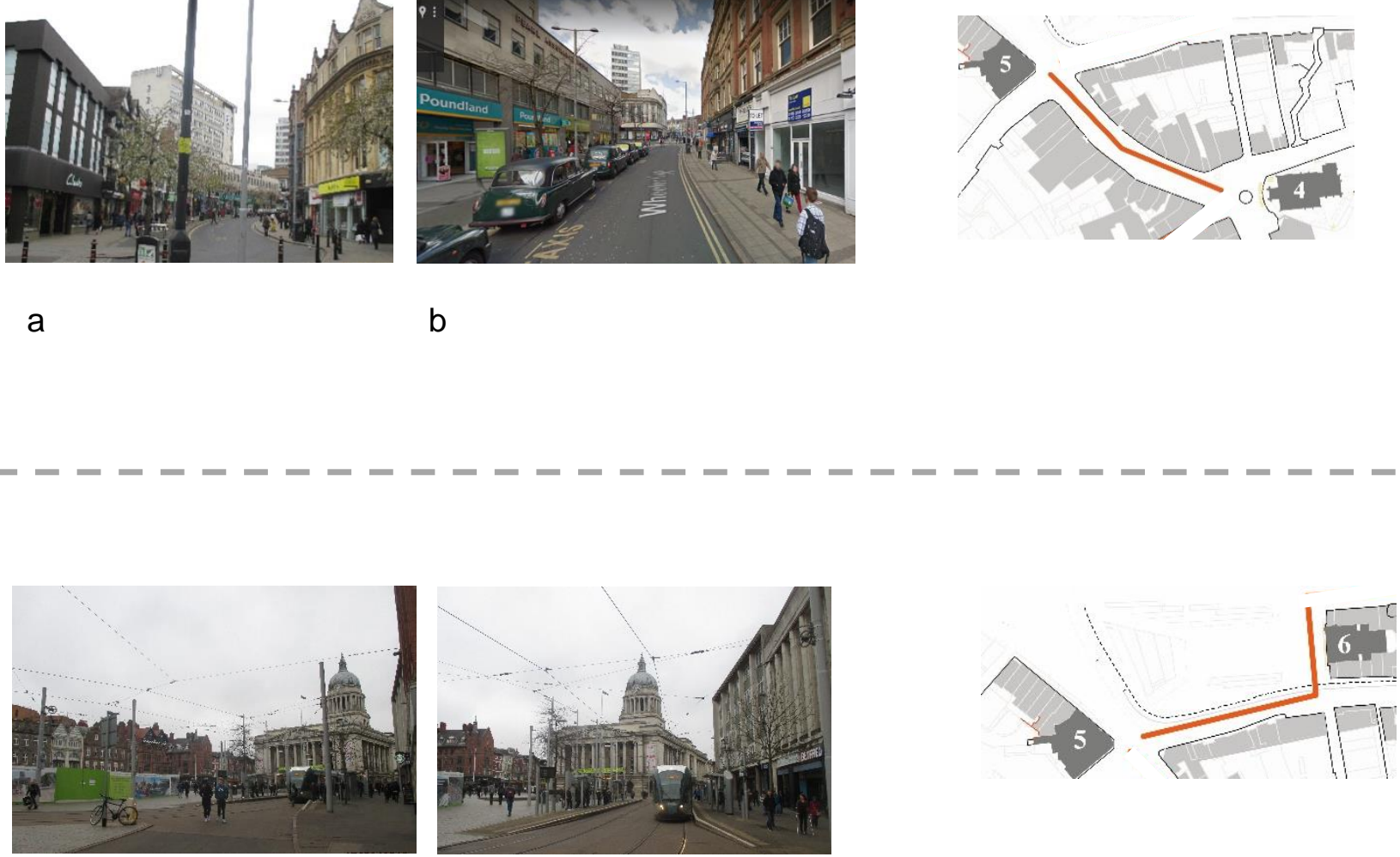

a

b
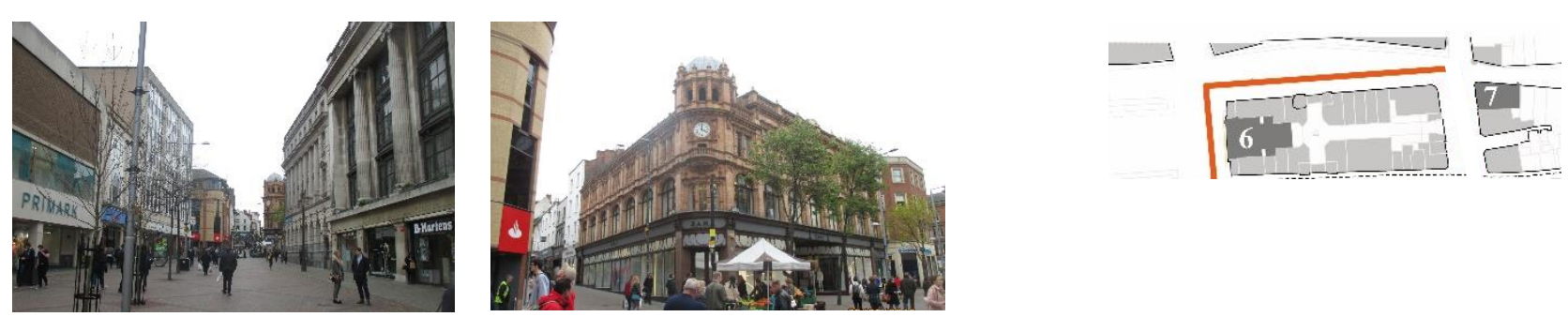

a

b

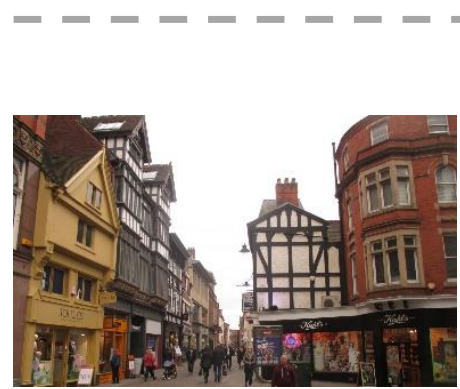

a
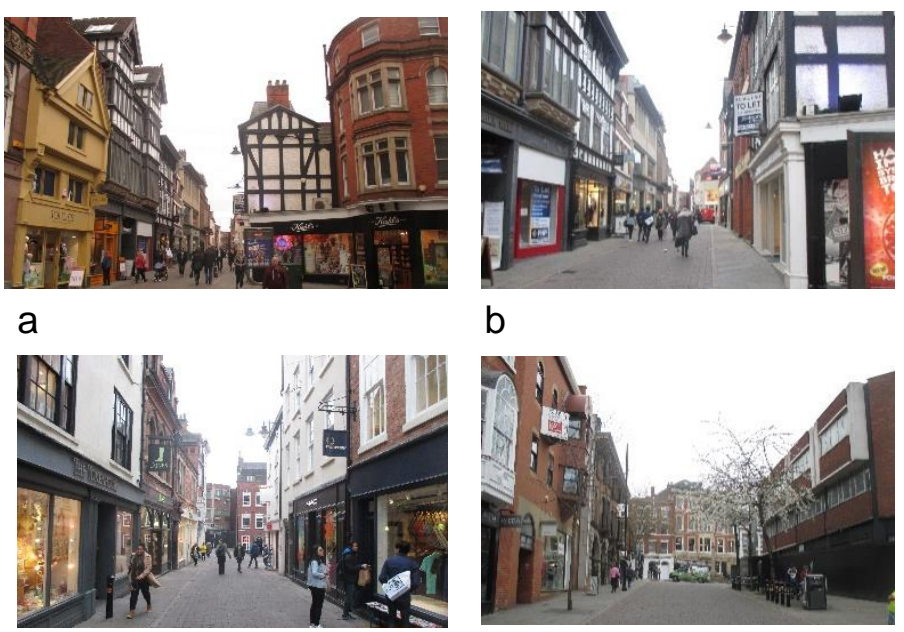

b

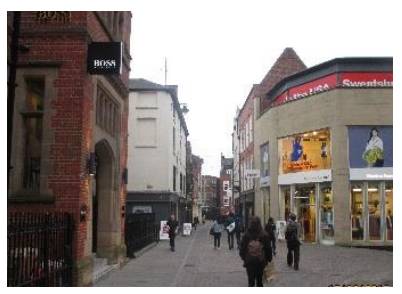

c
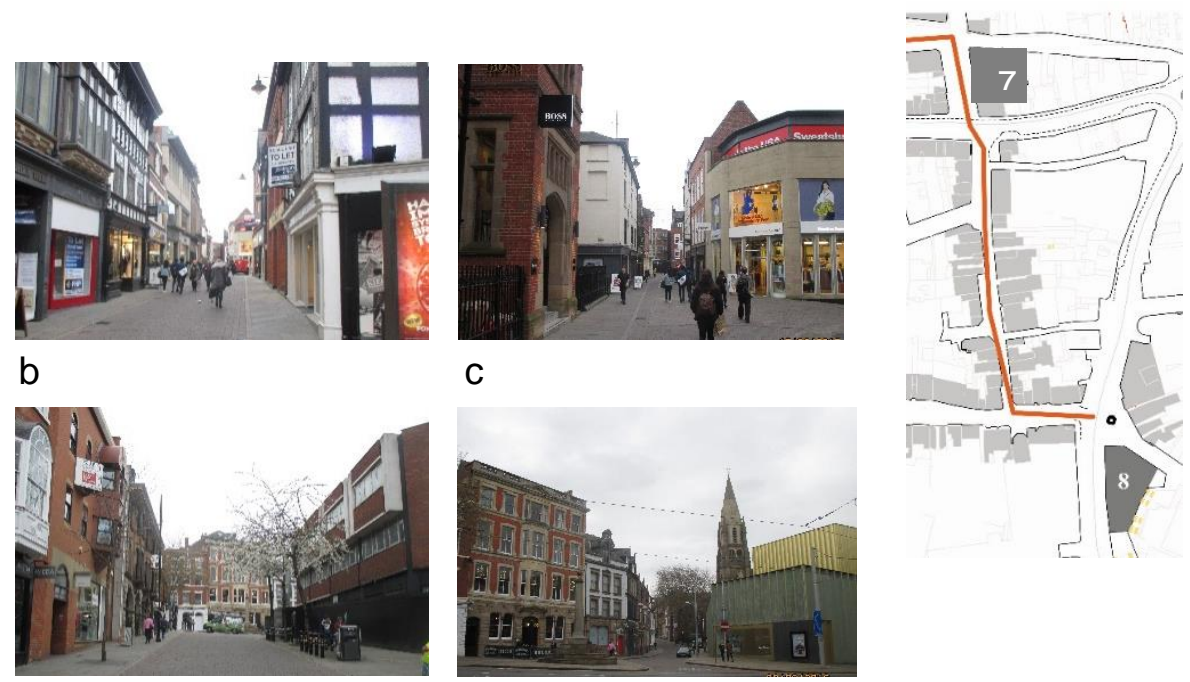

d

e

f

Figure 2: The integrated sequences that the participants went through along the route. 


\section{Experiment Design and Procedure}

Prior to the main research study, a pilot study had been conducted to ensure that both groups would use the same routes when travelling through the experimental setting. Before the experiment, DM participants were informed to familiarise themselves with the Google maps application (version 3.26) by practicing on the iPhone 6 provided by the researcher. The application displayed the participants' geographical location and heading direction, whilst automatically updating as they navigated the route. DM participants were shown how to enter the name of the destination into the app, and were instructed to follow the shortest suggested route on the map. Throughout the exercise, they were also able to zoom in and out the map they were using, in case they wished to view the map at a different scale. Once participants had signed their consent forms and completed the spatial assessment, they were individually taken to the starting location to begin the main task. The researcher ensured that each participant arrived at the starting point via a route that avoided any areas included in the test route, so as to avoid any form of confound (see figure 4).

The experiment was conducted in two phases. During Phase 1, participants in both the DM and DE groups were individually exposed to the experiment location. The experiment was designed to be as similar as possible to the everyday navigational behaviour experience when exposed to a new urban environment (i.e. some people use digital maps to navigate and others do not rely on any GPS assistance). The DM group were instructed to traverse the study area by sequentially navigating to a series of locations (i.e. eight locations), using their digital maps. Instructions were presented on an information sheet, following the paradigm specified by Willis et al. (2009), and required participants to find eight locations (using the shortest route suggested) within the test environment by using the mobile application. Each individual participant was 'shadowed' by two researchers, at a distance of twenty to thirty metres. If the participant went out of bounds of the test setting for ten minutes they were directed back to the site location where they had made the incorrect decision. If a participant believed that they had found the correct location, they were required to point it out and await 
confirmation from a researcher before moving onto the next location. The participants in the DE group were instructed to navigate to the same locations as the DM group, however, they could only do this by using physical directional signs and urban features within the study area. Otherwise, the DE group's procedure mirrored the DM group in all respects, apart from that they didn't have access to a digital navigation system (nor were they allowed to use their own).

In Phase 2 of the session, participants completed a recognition memory task, to probe their memory of the environmental features they had been exposed to. Following completion of Phase 1 , participants were led to a nearby location that afforded no view of the area they had just navigated (Figure 4). They were then provided with an iPad (iPad Pro 2016, 9.7in), upon which the recognition memory task was conducted. Participants were presented with full-screen colour photographs of urban scenes, all taken from eye level, and asked to report whether they remembered encountering those scenes along their routes or not. Three different types of environmental information were probed. Landmark memory was tested by presenting 16 photographs of buildings that had been encountered. All were distinct from their background (i.e. buildings with outstanding physical features or/and land use), and this was independently verified by two urban planners (not involved in this study) with an inter-rater reliability of $95 \%$. There were 16 foil photographs of similar buildings that had not been encountered along the route. Memory for nodes was tested by presenting participants with 18 photographs of nodes. These were taken at eye level photos, and depicted the nodes from the street that participants entered them that had been encountered along the route. There were 18 additional foil photographs of nodes that had not been encountered. Finally, path memory was assessed by presenting participants with 25 photographs of paths [Regarding the number of photos presented to the participants, for paths, depending on the number of path segments, participants were presented to different numbers of photos representing that path. For example, for a short path that the participants could see the end of the path from the start point, only one photo used, however, for a longer path, more photos were used to represent each 
segment of the path- if the path included two turns, three photos were used to represent the three segments of that path] that had been encountered along the route, along with 25 foil photographs of paths that had not been encountered.

Stimuli from all conditions were fully randomised, and presented to participants sequentially. At the bottom of each image were two boxes that participants were asked to press to register their response. Participants were instructed to choose either "yes", if they did remember encountering the scene, or "no" if they did not remember encountering the scene. Images remained onscreen until participants had made their response, and they volitionally began the subsequent trial by dragging the screen to the left in order to see the next photograph (see Figure 5). 

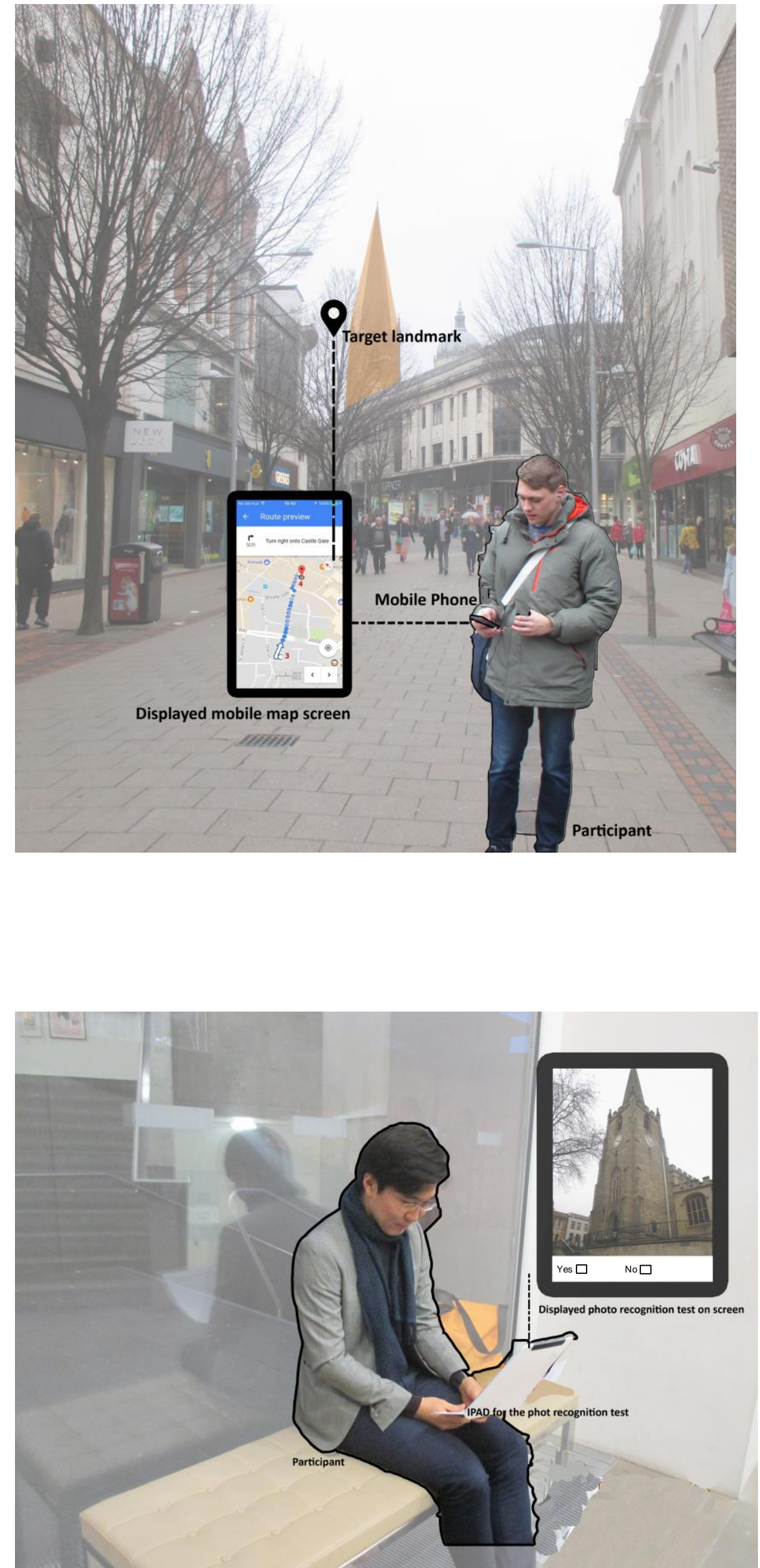

Figure 5: a DM participant is finding a target landmark in the site
Figure 5: a participant is accomplishing the recognition test 


\section{Results}

\section{Group comparisons}

The first phase of our analysis examined the influence of navigational support on the acquisition of spatial knowledge by comparing the accuracy of recognition memory between the two groups. The total of correct responses on each condition (landmarks, paths, nodes) was calculated for every participant. Accurate responses included hits (i.e. correctly responding 'yes' to targets) and correct rejections (i.e. responding 'no' to foils). Misses and false positives were both classed as incorrect responses. Recognition accuracy was then compared between DM and DE groups by using an independent samples t-test for each condition, as reported in Table 3. In all conditions, analyses revealed significantly greater accuracy in the DE group, compared to the DM group.

Table 3. Path Scores, Landmark Scores, and Node Scores for Digital Map Group (DM) and Direct Experience Group (DE)

\begin{tabular}{|c|c|c|c|c|c|c|c|c|c|c|}
\hline & & \multicolumn{2}{|c|}{ DM } & \multicolumn{2}{|c|}{$\mathrm{DE}$} & \multirow[t]{2}{*}{$\Delta \mathrm{M}$} & \multirow[t]{2}{*}{$\mathrm{t}$} & \multirow[t]{2}{*}{$d f$} & \multirow[t]{2}{*}{$\mathrm{p}$-value } & \multirow[t]{2}{*}{ Cohen's d } \\
\hline & & $\mathrm{M}(\mathrm{SD})$ & Range & $\mathrm{M}(\mathrm{SD})$ & $\begin{array}{c}\text { Rang } \\
\mathrm{e}\end{array}$ & & & & & \\
\hline 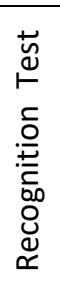 & $\begin{array}{l}\text { Participant } \\
\text { Path Score }\end{array}$ & $8.42(5.1)$ & $2-20$ & $\begin{array}{l}15.42 \\
(3.846)\end{array}$ & $5-48$ & 7.00 & -6.395 & 74 & $\begin{array}{c}* * * p \leq 0.0 \\
01\end{array}$ & $\begin{array}{l}0.95 \\
\text { large } \\
\text { effect }\end{array}$ \\
\hline 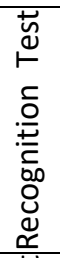 & $\begin{array}{l}\text { Participant } \\
\text { NodeScore }\end{array}$ & $5.11(3.42)$ & $1-16$ & $\begin{array}{l}11.47 \\
(6.70)\end{array}$ & $3-35$ & 6.36 & -5.107 & 74 & $\begin{array}{c}* * * p \leq 0.0 \\
01\end{array}$ & $\begin{array}{l}0.90 \\
\text { large } \\
\text { effect }\end{array}$ \\
\hline 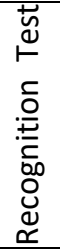 & $\begin{array}{l}\text { Participant } \\
\text { Landmark } \\
\text { Score }\end{array}$ & $\begin{array}{c}5.790 \\
(2.231)\end{array}$ & $2-10$ & $\begin{array}{c}11.290 \\
(6.80)\end{array}$ & $4-30$ & 5.5 & -4.730 & 74 & $\begin{array}{c}* * * p \leq 0.0 \\
01\end{array}$ & $\begin{array}{l}0.90 \\
\text { large } \\
\text { effect }\end{array}$ \\
\hline
\end{tabular}




\section{$\underline{\text { Route Comparisons }}$}

Subsequent analyses examined the impact upon different types of environmental feature upon recognition accuracy. For these tests, mean accuracy scores were compiled for each stimulus and then tested against their real-world physical properties. Separate analyses were carried out for both the DM and DE groups, to assess whether legibility had differential effects according to navigational experience.

Number of Turns. The number of turns within the experimental setting ranged between 0-6 ( $\mathrm{M}=$ $2.20, S D=1.881)$. Separate Pearson correlations were conducted between the number of turns and the mean recognition accuracy for path stimuli, and analyses revealed no significant correlation within either the DM group $(r=-0.3, p=0.08)$ and DE group $(r=-0.35, p=0.08)$ (See table 4). This suggests that recognition memory for paths is independent of the number of turns along the paths.

Street Length. The length of the route ranged from 110 to 800 metres $(M=339.150, S D=189.689)$. A Pearson correlation test revealed no significant relationship regarding street length and recognition memory for paths for the DM group $(r=-0.1, p=n . s$.$) and the DE group (r=.046, p=$ .272). Table 4 illustrates a correlation analysis for the number of turns and the length of a street on recognition memory for paths.

Table 4. Correlation analysis for the Number of Turns and Street Length on photo recognition accuracy

\begin{tabular}{|c|c|c|c|c|c|c|}
\hline & & & Number of Turns & & Length & \\
\hline & & & $r$ & $p$-value & $r$ & p-value \\
\hline 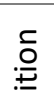 & & DM & -0.3 & n.s. & -0.1 & 0.07 n.s. \\
\hline 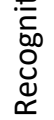 & $\stackrel{\mathscr{N}}{\mathscr{E}}$ & $\mathrm{DE}$ & -0.35 & n.s. & .046 & 0.09 n.s. \\
\hline
\end{tabular}

${ }^{* *}$ Correlation is significant at the 0.01 level (2-tailed). * Correlation is significant at the 0.05 level (2-tailed). 
Internal \& External Landmarks. The influence of landmarks upon path recognition was examined by separately comparing scenes of all the paths from the site (18 paths) on the basis of the presence or absence of internal landmarks, and also on the presence or absence of external landmarks.

Table 5. $t$ test analysis to compare the mean score of the streets with internal landmarks to those without internal landmarks

\begin{tabular}{|c|c|c|c|c|c|c|c|c|}
\hline & & & $\begin{array}{l}\text { With internal } \\
\text { landmark }\end{array}$ & $\begin{array}{l}\text { Without internal } \\
\text { landmark }\end{array}$ & $\Delta \mathrm{M}$ & $\mathrm{t}$ & $\mathrm{df}$ & $\mathrm{p}$-value \\
\hline & & & $M(S D)$ & $M(S D)$ & & & & \\
\hline \multirow{2}{*}{ 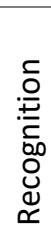 } & \multirow[b]{2}{*}{$\stackrel{\breve{y}}{\bullet}$} & DE M Score & 1.85 (0.35). & $1.00(0.30)$ & 0.85 & -4.88 & 18 & $* * * \mathrm{p} \leq 0.001$ \\
\hline & & DMM score & $1.70(0.30)$ & $1.00(0.40)$ & 0.70 & -4.18 & 18 & $* * * \mathrm{p} \leq 0.001$ \\
\hline
\end{tabular}

$* * * p \leq 0.001 ; * * p \leq 0.01 ;{ }^{*} p \leq 0.05 ;$ n.s.=not significant $(p>.05)$.

Accuracy for path stimuli were first compared on the basis of the presence or absence of an internal landmark (see Table 5). An independent samples t-test on data from the DM group revealed a significant difference between the streets with internal landmarks $(M=1.85, S D=0.30)$ and those without internal landmarks $(M=1.00, S D=0.40), t(18)=-4.88, p<0.001$. For the $D E$ group, the same relationship was revealed, with significantly greater recognition accuracy for paths with internal landmarks $(M=1.85, S D=0.30)$, compared to those without internal landmarks $(M=1.00, S D=0.30), t$ $(18)=-1.90, p<0.001$

The same tests were applied to path accuracy on the basis of the presence of external visible landmarks (see Table 6). An independent samples t-test on data from the DM group revealed a significant difference between paths with external landmarks $(M=1.80, S D=0.31)$ and those without $(M=1.10, S D=0.51), t(18)=-1.84, p \leq 0.05$. This was also the case for participants in the $D E$ group, 
with significantly greater accuracy for paths with external landmarks $(M=1.90, S D=0.33)$, compared to those without $(M=1.10, S D=0.5), t(18)=-1.31, p<0.05$.

Table 6. $t$ test analysis to compare the mean score of the streets with external landmarks to those without external landmarks.

\begin{tabular}{|c|c|c|c|c|c|c|c|c|}
\hline & & & $\begin{array}{l}\text { With external } \\
\text { landmark }\end{array}$ & $\begin{array}{l}\text { Without external } \\
\text { landmark }\end{array}$ & $\Delta \mathrm{M}$ & $\mathrm{t}$ & $\mathrm{df}$ & p-value \\
\hline \multirow{2}{*}{ 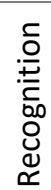 } & \multirow[b]{2}{*}{ 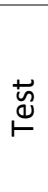 } & DE M Score & $1.90(0.33)$ & $1.10(0.5)$ & 0.80 & -1.31 & 18 & $0.047^{*} p \leq 0.05$ \\
\hline & & DM M score & $1.80(0.31)$ & $1.10(0.51)$ & 0.70 & -1.84 & 18 & $0.040 * p \leq 0.05$ \\
\hline
\end{tabular}

Node Comparisons. Recognition accuracy for nodes was examined on the basis of two different legibility factors: the number of node legs, and the presence or absence of landmarks on nodes. The number of node legs (which refers to the number of paths entering a node) ranged between 3-6 legs $(M=3.750, S D=1.020)$. For stimuli in the node condition, Pearson correlation tests revealed no significant relationship between the mean score for the nodes and the number of legs for either DE or DM groups (see Table 7).

To test for an effect of the presence of landmarks at nodes, an independent t-test revealed that the DE group had a significantly higher mean accuracy scores whenever there were landmarks present on the nodes $(M=1.85, S D=0.20)$ compared to nodes without landmarks $(M=1.00, S D=0.10) ; t(18)$ $=-12.60, p<0.001$. The same relationship was revealed for the DM group, with higher accuracy for for nodes with landmarks $(M=1.90, S D=0.20)$ compared to nodes without landmarks $(M=1.20, S D=$ $0.163) ; \mathrm{t}(18)=-8.180, \mathrm{p}<0.001$ (see Table 8). 
Table 7. Correlation analysis

\begin{tabular}{|c|c|c|c|c|}
\hline & & & \multicolumn{2}{|c|}{ Number of Legs } \\
\hline & & & $r$ & $p$-value \\
\hline \multirow{2}{*}{ 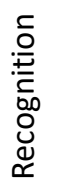 } & \multirow{2}{*}{ 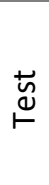 } & DM & 0.102 & 0.661 n.s. \\
\hline & & $\mathrm{DE}$ & 0.075 & 0.75 n.s. \\
\hline
\end{tabular}

Table 8. t-test analysis to compare the mean score of the Nodes with Landmarks to Nodes without Landmarks.

\begin{tabular}{|c|c|c|c|c|c|c|c|c|c|}
\hline & & & $\begin{array}{l}\text { Nodes with } \\
\text { a landmark }\end{array}$ & $\begin{array}{l}\text { Nodes without } \\
\text { a landmark }\end{array}$ & $\Delta \mathrm{M}$ & $\mathrm{t}$ & $d f$ & $\mathrm{p}$-value & Cohen's d \\
\hline & & & $M(S D)$ & $M(S D)$ & & & & & \\
\hline \multirow{2}{*}{ 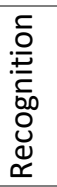 } & \multirow{2}{*}{ 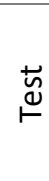 } & $\begin{array}{l}\text { DM M } \\
\text { Score }\end{array}$ & $1.85(0.20)$ & $1.00(0.10)$ & 0.85 & -12.60 & 18 & $* * * \mathrm{p} \leq 0.001$ & $\begin{array}{l}\text { Large } \\
\text { effect }\end{array}$ \\
\hline & & $\begin{array}{l}\text { DE M } \\
\text { score }\end{array}$ & $1.90(0.20)$ & $1.20(0.163)$ & 0.70 & -8.180 & 18 & $* * * p \leq 0.001$ & $\begin{array}{l}\text { Large } \\
\text { effect }\end{array}$ \\
\hline
\end{tabular}

Landmark Comparisons. Final analyses focused on comparison between landmark accuracy on the basis of visibility. To evaluate the visibility for each landmark, an adapted version of the scale used by Appleyard (1969) was adopted. Accordingly, the visibility of the landmarks listed in this study were rated according to three attributes: a) immediacy - the landmark's measure of distance and centrality to the line of view; b) proximity to the main decision points - the landmark's presence at important decision points and points of transitions; and c) significance of viewpoint - an estimate of the number of people who might see the landmark regularly from its most commonly used viewpoint. This final attribute was measured by estimating the number of pedestrians during a typical day that are likely to pass by the viewpoint of the landmarks that our participants passed by in the experiment. This was an approximate measure, as accurate flow data did not exist (Appleyard, 1969; Hassan, 1965). The landmarks were then rated from low to high on a three-point Likert scale. 
In order to measure if the degree of visibility for landmarks affected the ability in visual recognition of landmarks, a Pearson's correlation between the visibility attributes (for each landmark) and the mean landmark scores (i.e. mean of participants' scores for each landmark, using the schema-based analyses) was employed (see Table 9).

Table 9. Correlation analysis of landmark visibility and mean landmark score

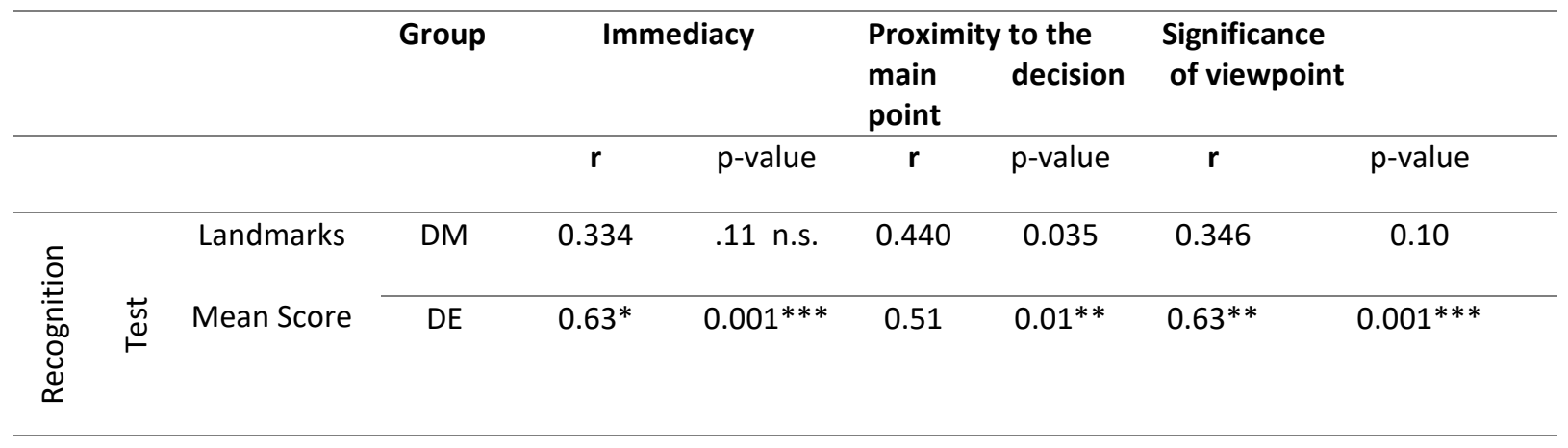

** Correlation is significant at the 0.01 level (2-tailed) - *Correlation is significant at the 0.05 level (2tailed).

Analysis of DM data did not reveal a significant correlation between mean landmark recognition accuracy and any of the visual factors: immediacy $(r=0.334, N=23, p=n . s$.$) ; proximity to the main$ decision point ( $r=0.440, N=23, p=n . s$.$) ; and, significance of viewpoint (r=0.346, N=23, p=n . s$.$) .$ However, in the DE group, there was a significant correlation between landmark accuracy and all three factors: immediacy $(r=0.63, N=23, p=0.001)$; proximity to the main decision point $(r=0.51$, $\mathrm{N}=23, \mathrm{p}=0.01)$; and, significance of viewpoint $(r=0.63, \mathrm{~N}=23, \mathrm{p}=0.001)$. 


\section{Discussion}

We have presented novel data from an experiment that was originally designed to address two questions. The first is how use of a mobile navigation device affects the user's memory for environmental features, and the second is how the legibility of those features modulates the likelihood of users being able to remember them. We have recently published findings that assessed this knowledge through the use of sketch map drawings (see Ahmadpoor \& Smith, 2020). However, whilst sketch maps provide a rich assay of an individual's conscious recollection of an allocentric environmental layout, there may be other information that is less immediately accessible to the individual. Furthermore, individual differences in, say, drawing ability or mental imagery may lead to a lot of variability between users. Here we have presented new recognition memory data, from the same sample, which provides a more sensitive measure of spatial memory, whilst also allowing us to compare this alternative to our previous findings. Finally, augmentation of the empirical picture through more formalised testing of recognition memory (albeit in-field, rather than in the laboratory) can further inform urban design guidelines.

The dataset revealed that individuals in the DM group had poorer recognition memory for the routes they had followed. This means that they were less accurate in recognising properties of the environment that they had encountered, as well as less accurate at correctly rejecting properties of an environment that they had not encountered. This group performed more poorly than DE participants in all three conditions that (respectively) tested recognition for landmarks, paths, and nodes. These data confirmed our predictions and are in alignment with the sketch map data that we have previously reported Ahmadpoor and Smith (2020). They are also consistent with prior studies conducted by Willis et al. (2009), Dickmann (2012), Krüger, Aslan and Zimmer (2004), and Münzer et al. (2006), which have all highlighted a relative paucity of environmental knowledge in digital map users, compared to navigators using paper maps/direct experience (see also: Parush, Ahuvia and 
Erev (2007a), Klippel, Hirtle and Davies (2010), and Aslan et al., (2006). The general picture also accords with related findings from studies such as that of Gardony et al.'s (2013), which identified the importance of user engagement with an environment for effective spatial learning, and that of Wen, Ishikawa and Sato (2011), which reported lower recognition memory for path information in GPS users (compared to direct experience navigators).

Additional analyses examined how recognition memory of the environment in the DM and DE groups was affected by environmental legibility. Prior to the study, it was anticipated that the recognition memory of the environment in DE navigators would be affected by environmental legibility, as evidenced in prior research by Westerbeek and Maes (2013). However, before conducting the present study it was unclear if the DM group would be affected in a similar way, given their navigational assistance. It was possible to assess the impact of different components of legibility by comparing routes that had greater or fewer instances of these elements, in order to provide a more precise indication of how the DM groups might have been affected. Analysis revealed that several factors were responsible for affecting the recognition memory of the environment for both DE and DM navigators, namely the presence of internal and external landmarks along a path, as well as the presence of a landmark at a node.

Interestingly, according to the results of current report, the intersections that had landmarks at their corners were visually recognised significantly better than the intersections without landmarks, in both groups. This supports the research of Haque, Kulik and Klippel (2006), which showed that an individual's spatial representation increased whenever there was a landmark at an intersection. Likewise, according to the report by Ahmadpoor and Smith (2020), the nodes that had landmarks placed at their corners were depicted significantly more accurately in both DM and DE groups' sketch maps which reflect their mental maps. A reason as to why the presence of landmarks at intersections would affect the DM group is that they might have assisted in the process of relating 
their digital representation of the space to the real-world equivalent. Indeed, such points would often be marked on the digital maps owing to their being of historical, structural, or cultural significance in the urban setting.

Löwen et al. (2019) report that, despite various methods being used to include landmarks for navigators, it is still unclear which strategy of landmark placement is most beneficial for spatial knowledge acquisition. Additionally, clearly agreeing on definitions of landmarks may have played a factor. For example, external landmarks (those visible to navigators but not in the immediate vicinity of the path) are not seen as being equated with internal landmarks (those in the immediate location of the path). Indeed, studies by Klippel, Richter and Hansen (2005) and Westerbeek and Maes (2013) have argued that internal landmarks are more closely linked to environmental comprehension. Our recognition data also revealed that both internal and external landmarks had a significant influence on recognition memory for paths that had been traversed. However, data from our previous report revealed that internal and external landmarks did not assist DM users in their ability to accurately depict the paths in their sketch maps (Ahmadpoor and Smith, 2020). This might, therefore, reflect the increased sensitivity of a recognition paradigm, since the factors clearly affected mental representation of information for DM participants. It might also reflect the quality of representation required to respond to an experimental probe - recognising a landmark requires less detailed knowledge than being able to construct a configural cognitive map of the environment explored and to accurately place that landmark within it (which is what the sketch map paradigm required). Our additional analysis of landmark memory based on their visual properties revealed that neither immediacy to the participant's line of sight, nor the significance of the landmarks viewpoint, had an effect on the DM group's memory for internal landmarks. In contrast, immediacy of the internal landmark to the navigator's line of sight, the significance of the viewpoint for observing the landmark, and proximity to the main decision point (i.e. a node), all had a considerable effect on recognition memory in the DE group. This indicates that when participants were using Digital Maps 
for navigation, they could have easily missed the landmarks on their way, even when they were directly in their line of sight.

According to Ahmadpoor and Smith (2020), the design of junctions (e.g. the number of streets entering them and the landmarks placed at the junction) showed a robust impact on the spatial knowledge of digital maps users. Also, amongst each of the legibility factors tested in the present analyses, the presence of landmarks in the site, whether at intersections or along the paths, has been shown to have a significant impact on the visual recognition ability of digital map users. For the urban design profession, our findings suggest that, in order for digital map assisted users to better comprehend the built environment, placing a landmark at the corner of a junction can increase the legibility of the junction for such users. This is in line with general design policy for junctions that they should have visual clarity in design to be legible for navigators (Department of the Environment andTransport and the Regions, 2000; CABE, 2003). Implementing this in urban design projects can fall into two categories: a) designing junctions in new development projects; and b) the adaptation of existing junctions in regeneration projects. In new development projects, it is easier to design a junction to meet the criteria suggested here, however, in regeneration projects, modifying a junction to have a more clarity could face some significant contextual design limitations that need to be taken into account. Also, placing landmarks at the intersection and along the path (whether internal or external) can help DM users to gain a better visual understanding of the built environment. These landmarks may not necessarily contribute to the accuracy of locational knowledge, and yet they help digital map users to build some form of representation of the site, which can itself assist navigation. The policies for 'good design' also suggest that presence of landmarks in the built environment can reinforce the sense of place, visual identity and recognition memory of people (Department of the Environment andTransport and the Regions, 2000; CABE, 2003). 
In summary, although landmarks alone did not help DE and DM participants to build an accurate mental map of the area (Ahmadpoor and Smith, 2020), the data we present here reveals that landmarks in the built environment, whether at intersections or along paths, significantly contribute to recognition memory of the built environment for all navigators. The difference between sketch map data and recognition data shows that people might not always have conscious access to the contents of their mental spatial representations - i.e. some information may not be sufficiently detailed or elaborated for it to inform the creation of an allocentric configural cognitive map. However, recognition performance in these data reveals that a finer grain of understanding can be achieved if one applies the right tool. This, therefore, argues for a more comprehensive armoury of measures when we assess the experiences and subsequent spatial representations of navigators. It also suggests that urban designers should attend to both location and spatial aspects of landmarks when considering the built environment, in order to support its legibility and support the variety of mental representations that are constructed by navigators as a result of their different experiences (see figure 6).

These data also suggest more specific considerations that could be adopted by urban designers. For example, there is a clear need for a more formal identification of the physical characteristics (e.g. colour, material, height, etc.) of the landmarks that digital map users do successfully recognise. In addition, it will be important to examine how the inclusion of additional features, such as audio information, on an interactive map can affect spatial knowledge, and recognition memory. For example, Klatzky et al. (1990) report that systems that provided audio feedback was beneficial for navigation. Along this vein, our future research is intended to examine how the use of Google maps (or similar navigation applications) with voice-assisted navigation affects a navigator's ability to acquire spatial knowledge. Ultimately, the accumulation of this data, alongside our existing body of knowledge, will provide more accurate predictions as to how an urban setting may be designed to improve the efficiency of all types of navigator. 


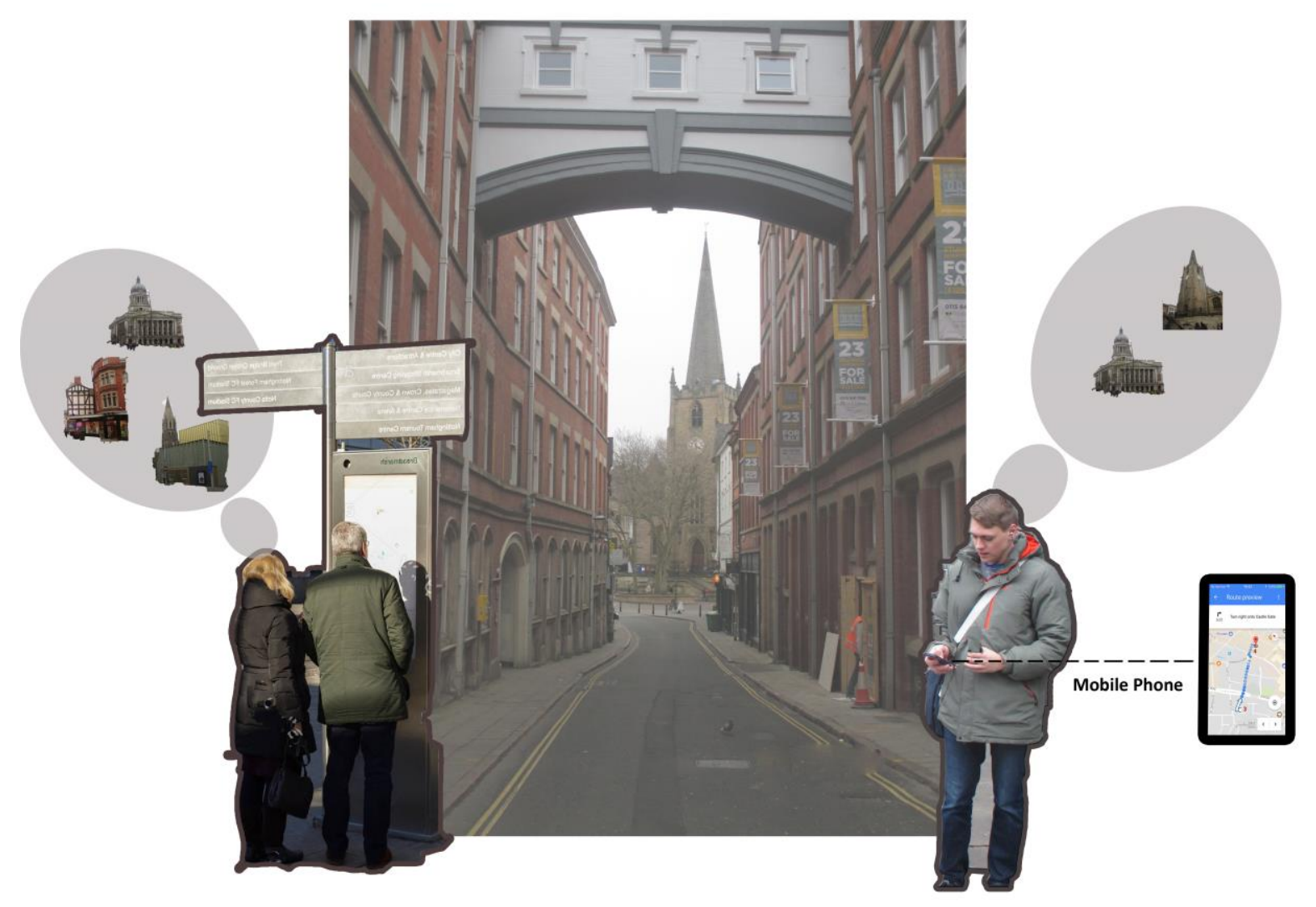

Direct Experience Participants (DE)

Digital Mobile Map Participants (DM)

\section{Experiment Results Summarv}

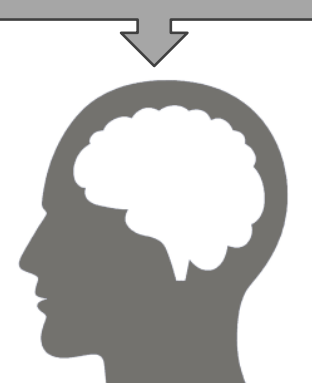

Landmarks at the intersections and along the paths contributed to the Recognition Memory for both DE and DM participants

\section{Urban Desian Suqqestions}

Placing attention on locational and spatial design of the landmarks that can improve the environmental legibility and recognition memory for people who navigate the environment whether directly or through using digital mobile maps

Figure 6: Summary of results and conclusion 


\section{References}

Ahmadpoor, N. \& Heath, T. 2018. Data and GPS systems: Comparing navigation and landmark knowledge between GPS users and non-GPS users. Data, Architecture and the Experience of Place. London: Routledge.

Ahmadpoor, N. and Smith, A.D., 2020. Spatial knowledge acquisition and mobile maps: The role of environmental legibility. Cities, 101, p.102700.

Ahmadpoor, N. and Shahab, S., 2019. Spatial knowledge acquisition in the process of navigation: A review. Current Urban Studies, 7(1), pp.1-19.

Appleyard, D. (1970) 'Styles and methods of structuring a city', Environment and Behavior 2(1): 100117.

Aslan, I., Schwalm, M., Baus, J., Krüger, A. and Schwartz, T. 'Acquisition of spatial knowledge in location aware mobile pedestrian navigation systems'. Proceedings of the 8th conference on Humancomputer interaction with mobile devices and services: ACM, 105-108.

Bakdash, J. Z., Linkenauger, S. A. and Proffitt, D. 'Comparing decision-making and control for learning a virtual environment: Backseat drivers learn where they are going'. The Human Factors and Ergonomics Society Annual Meeting, Sage CA: Los Angeles: SAGE: 2117-2121.

Bristol City Council (2003) Building Legible Cities. Bristol: Bristol Cultural Development Partnership. Bristol City Council, Regeneration, g.a. (2018) URBAN LIVING SPD. Bristol Bristol City Council. Brügger, A., Richter, K. F. and Fabrikant, S. I. (2019) 'How does navigation system behavior influence human behavior?.', Cognitive Research: Principles and Implications, 4(1): 5.

CABE, Environment, C.f.A.a.t.B. (2003) THE COUNCILLOR'S GUIDE TO URBAN DESIGN. London.

CABE and DETR (2001) The Value of Urban Design: A research project commissioned by CABE and DETR to examine the value added by good urban design, London CABE and DETR

Dai, R., Thomas, A.K. and Taylor, H. A. (2018) 'When to look at maps in navigation: metacognitive control in environment learning. ', Cognitive Research: Principles and Implications, 3(1): 36.

Cohen, R. and Schuepfer, T., 1980. The representation of landmarks and routes. Child development, pp.1065-1071.

Cui, X., Jeter, C. B., Yang, D., Montague, P. R., \& Eagleman, D. M. (2007). Vividness of mental imagery: individual variability can be measured objectively. Vision research, 47(4), 474-478

Department of the Environment andTransport and the Regions (2000) By design: Urban design in the planning system: towards better practice. London: Commission for Architecture and the Built Environment. 
Dickmann, F. (2012) 'City maps versus map-based navigation systems-an empirical approach to building mental representations. ', The Cartographic Journal, 49(1): 62-69.

Downs, R. M. and Stea, D. (1973) Image and environment: Cognitive mapping and spatial behavior. Transaction Publishers.

Evans, G.W., Brennan, P.L., Skorpanich, M.A. and Held, D., 1984. Cognitive mapping and elderly adults: Verbal and location memory for urban landmarks. Journal of Gerontology, 39(4), pp.452-457.

Ralphs, E., Shahab, S. and Ahmadpoor, N., 2020. Access to Small Airports and the Impact on Regional Growth in the UK. Current Urban Studies, 8(01), p.24.

Gao, Y., Shahab, S. and Ahmadpoor, N., 2020. Morphology of Urban Villages in China: A Case Study of Dayuan Village in Guangzhou. Urban Science, 4(2), p.23

Gardony, A. L., Brunyé, T. T., Mahoney, C. R. and Taylor, H. A. (2013) 'How navigational aids impair spatial memory: Evidence for divided attention.', Spatial Cognition \& Computation, 13(4): 319-350.

Gärling, T., Lindberg, E. and Mäntylä, T. (1983) 'Orientation in buildings: Effects of familiarity, visual access, and orientation aids', Journal of Applied Psychology, 68(1): 177.

Golledge, R. G. (1978) 'Learning about urban environments', in Carlstein, T., Parkes, D. \& THrift, N. (eds) Timing Space and Spacing Time Vol. I: Making Sense of Time.

Golledge, R. G., Jacobson, R. D., Kitchin, R. and Blades, M. (2000) 'Cognitive maps, spatial abilities, and human wayfinding', Geographical Review of Japan, Series B., 73(2): 93-104.

Guérard, K. and Tremblay, S. (2012) 'The effect of path length and display size on memory for spatial information', Experimental Psychology 59(3): 147-152.

Haque, S. (2003) 'Investigating the syntax line: configurational properties and cognitive correlates', Environment and Planning B: Planning and Design, 30(6): 841-863.

Haque, S. and Zimring, C. (2003) 'Just down the road a piece the development of topological knowledge of building layouts', Environment and behavior, 35(1): 132-160.

Haque, S., Kulik, L. and Klippel, A. (2006) 'Algorithms for reliable navigation and wayfinding'. International Conference on Spatial Cognition: Springer:308-326.

Hegarty, M., Richardson, A. E., Montello, D. R., Lovelace, K. and Subbiah, I. (2002) 'Development of a self-report measure of environmental spatial ability', Intelligence, 30(5): 425-447.

Ishikawa, T., Fujiwara, H., Imai, O. and Okabe, A. (2008) 'Wayfinding with a GPS-based mobile navigation system: A comparison with maps and direct experience', Journal of Environmental Psychology, 28(1): 74-82. 
Ishikawa, T. and Takahashi, K. (2013) ' Relationships between methods for presenting information on navigation tools and users' wayfinding behavior', Cartographic Perspectives, 75: 17-28.

Jansen-Osmann, P. and Wiedenbauer, G. (2004) 'The influence of turns on distance cognition: New experimental approaches to clarify the route-angularity effect', Environment and Behavior, 36(6): 790-813.

Klatzky, R. L., Loomis, J. M., Golledge, R. G., Cicinelli, J. G., Doherty, S. and Pellegrino, J. W. (1990) 'Acquisition of route and survey knowledge in the absence of vision', Journal of motor behavior, 22(1): 19-43.

Klippel, A., Hirtle, S. and Davies, C. (2010) 'You-are-here maps: Creating spatial awareness through map-like representations.', Spatial Cognition \& Computation, 10(2-3): 83-93.

Klippel, A., Richter, K. F. and Hansen, S. (2005) Structural salience as a landmark, in Workshop Mobile Maps, Salzburg, Austria.

Krüger, A., Aslan, I. and Zimmer, H. 'The effects of mobile pedestrian navigation systems on the concurrent acquisition of route and survey knowledge'. International Conference on Mobile HumanComputer Interaction: Springer: 446-450.

Llewelyn Davies (2000) Urban Design Compendium: Homes and Communities Agency.

Long, Y. and Baran, P. K. (2012) 'Does intelligibility affect place legibility? Understanding the relationship between objective and subjective evaluations of the urban environment', Environment and Behavior, 44(5): 616-640.

Löwen, H., Krukar, J. and Schwering, A. (2019) ' Spatial learning with orientation maps: The influence of different environmental features on spatial knowledge acquisition.', ISPRS International Journal of Geo-Information, 8(3): 149.

Lynch, K. (1960) The Image of the City. MIT Press, Cambrdige Massachusetts.

Münzer, S., Zimmer, H. D., Schwalm, M., Baus, J. and Aslan, I. (2006) 'Computer-assisted navigation and the acquisition of route and survey knowledge', Journal of Environmental Psychology, 26(4): 300-308.

Nothegger, C., Winter, S. and Raubal, M. (2004) 'Selection of salient features for route directions. ', Spatial cognition and computation, 4(2): 113-136.

Nottingham City Council (2009) NOTTINGHAM CITY CENTRE URBAN DESIGN GUIDE. Manchester: URBED.

Nottingham City Council (2019) Design quality framework: Improving design quality through Placemaking. Nottingham Nottingham City Council. 
Parush, A., Ahuvia, S. and Erev, I. 'Degradation in spatial knowledge acquisition when using automatic navigation systems', International Conference on Spatial Information Theory, Berlin, Heidelberg: 238-254.

Passini, R. (1984) 'Spatial representations, a wayfinding perspective', Journal of environmental psychology, 4(2): 153-164.

Presson, C. C. and Montello, D. R. (1988) 'Points of reference in spatial cognition: Stalking the elusive landmark', British Journal of Developmental Psychology, 6(4): 378-81.

Raubal, M. and Winter, S. 'Enriching wayfinding instructions with local landmarks', International Conference on Geographic Information Science, Berlin, Heidelberg: Springer.

Richter, K.-F. 'Adaptable path planning in regionalized environments'. International Conference on Spatial Information Theory: Springer, 453-470.

Richter, K.-F. and Klippel, A. 'A model for context-specific route directions'. International Conference on Spatial Cognition: Springer, 58-78.

Ruginski, I. T., Creem-Regehr, S. H., Stefanucci, J. K. \& Cashdan, E. 2019. GPS use negatively affects environmental learning through spatial transformation abilities. Journal of Environmental Psychology, 64, 12-20.

Schwering, A., Wang, J., Chipofya, M., Jan, S., Li, R. and Broelemann, K. (2014) 'SketchMapia: Qualitative representations for the alignment of sketch and metric maps.', Spatial Cognition \& Computation, 14(3): 220-254.

Shahab, S., Clinch, J.P. and O'Neill, E., 2019a. Impact-based planning evaluation: Advancing normative criteria for policy analysis. Environment and Planning B: Urban Analytics and City Science, 46(3), pp.534-550.

Shahab, S., Clinch, J.P. and O'Neill, E., 2019b. An analysis of the factors influencing transaction costs in transferable development rights programmes. Ecological economics, 156, pp.409-419.

Sheffield City Council, Planning, d.a.c. (2004) SHEFFIELD CITY CENTRE. Sheffield

Siegel, A. W. and White, S. H. (1975) 'The development of spatial representations of large-scale environments', Advances in Child Development and Behavior, 10: 9-55.

Speake, J. (2015) 'I've got my Sat Nav, it's alright': Users' Attitudes towards, and Engagements with, Technologies of Navigation', The Cartographic Journal, 52(4): 345-355.

The Essex Design Guide, Association, E.P.O. (2018) Legibility. Essex.

Thorndyke, P. W. and Hayes-Roth, B. (1982) 'Differences in spatial knowledge acquired from maps and navigation', Cognitive Psychology, 14(4): 560-589. 
Van Sommers, P. (1984). Drawing and cognition: Descriptive and experimental studies of graphic production processes. Cambridge University Press.

Weisman, J. (1981) 'Evaluating architectural legibility way-finding in the built environment', Environment and behavior, 13(2): 189-204.

Wen, W., Ishikawa, T. and Sato, T. (2011) 'Working memory in spatial knowledge acquisition: Differences in encoding processes and sense of direction', Applied Cognitive Psychology, 25(4): 654662.

Westerbeek, H. and Maes, A. (2013) 'Route-external and route-internal landmarks in route descriptions: Effects of route length and map design', Applied Cognitive Psychology, 27(3): 297-305.

Willis, K. S., Hölscher, C., Wilbertz, G. and Li, C. (2009) 'A comparison of spatial knowledge acquisition with maps and mobile maps', Computers, Environment and Urban Systems, 33(2): 100-110. 